\title{
LOS RELATOS DE VIAJE KAWÉSQAR, SU ESTRUCTURA Y REFERENCIA DE PERSONAS
}

OSCAR E. AGUILERA F.

\section{RESUMEN}

En este artículo se examina la estructura de los relatos de viaje kawésqar y la referencia a personas en ellos, aspecto no abordado hasta el presente en el estudio del discurso de esta lengua fueguina en peligro.

PALABRAS CLAVE: Lenguas fueguinas, kawésqar, literatura oral kawésqar, narrativa, relatos de viaje, análisis del discurso, referencia de personas.

\section{KAWESQAR TRAVEL NARRATIVES. STRUCTURE AND PERSON REFERENCE}

\section{ABSTRACT}

This article examines the structure of Kawesqar travel narratives and participant reference in them, an aspect in the study of Kawesqar discourse not dealt with up to now.

KEY WORDS: Fueguian languages, Kawesqar, Kawesqar oral literature, narrative, travel narratives, discourse analysis, participant reference.

\section{INTRODUCCIÓN}

\section{Aspectos generales}

Los relatos de viaje forman parte de la literatura oral kawésqar junto con los relatos de mitos.
En un trabajo de rescate del acervo cultural de esta etnia realizado en $2006-2007^{1}$ fue posible registrar un buen número de este tipo de narraciones. Un Proyecto FONDECYT ${ }^{2}$ realizado entre 2008-2009 permitió obtener una versión bilingüe de siete relatos, (Aguilera-Tonko, 2010).

Etnolingüista, investigador de FIDE XII, Punta Arenas, Chile. oscaraguileraf@gmail.com.

1 Proyecto financiado por el Gobierno Regional de Magallanes y Antártica Chilena, administrado por CONADI, XII Región y ejecutado por FIDE XII, en Punta Arenas, Puerto Edén y Santiago, con la activa participación de miembros de la Comunidad Kawésqar de Puerto Edén.

2 Proyecto FONDECYT No. 1085204 (2008-9) "El relato de viaje en la literatura oral kawésqar". Este artículo constituye parte de esa investigación. 
Los relatos de viaje kawésqar no sólo describen las travesías a lo largo de su territorio que se extendía desde el golfo de Penas hasta el estrecho de Magallanes, sino que en ellos se ilustra en forma particularizada las técnicas de navegación, de recolección, caza, pesca, construcción de la vivienda temporal, la cultura material, la interacción social, religiosidad, ecosistema; en fin, todo lo relativo a la vida en los canales de la Patagonia occidental. Por ello son ricas fuentes de información del sistema de vida kawésqar y su entorno. Los relatos de viaje son el reflejo testimonial más directo de la vida cotidiana de este pueblo nómade, por lo cual proporcionan respuestas a problemas planteados por otros especialistas como Martin Gusinde y Joseph Emperaire, o corrigen interpretaciones erróneas.

Por ejemplo, Emperaire, (1966: 65-66), no se explica por qué los kawésqar frecuentaban asiduamente la porción hacia el Pacífico de su territorio, denominada málte en lengua kawésqar:

En su vida errante, los alacalufes tenían una preferencia marcada por ciertos sitios próximos al Pacífico que llegaban a ser así lugares de paso y de habitación temporal muy frecuentados. Nadie podría decir por qué ni explicar las razones de esta preferencia, tal vez sentimental. Las islas y canales que están cerca del Pacífico son más inhospitalarios que los otros. Sin embargo, si nos fundamos en el número de nacimientos y defunciones que se han producido allí en una época reciente, se puede estimar que el canal Fallos, los archipiélagos Guayaneco y Madre de Dios, la red complicada de canales entre el canal Castillo y el canal Ladrillero, el Brazo Norte y el Canal Picton eran centros preferidos de estancia.

La razón del desplazamiento a la costa exterior (málte) se debe fundamentalmente a la caza y recolección estacional. Los canales Fallos, Ladrillero y Picton, mencionados por Emperaire son las rutas que conducen a las zonas de caza y recolección del mar exterior. Las zonas de nidificación se encuentran en la costa exterior y el traslado a ellas se efectuaba durante el período llamado jekékste o jesékte tiempo de huevos ${ }^{3}$, como en la cita siguiente $e^{4}$.

3 Jekékste (o la variante jakákste) significa tiempo de crías, que se usa indistintamente para referirse al tiempo de puesta de huevos como del nacimiento de mamíferos marinos.

4 En las transcripciones se utiliza el Alfabeto Estándar Kawésqar.
(1)

Jolawókstai aqálap-ho, aqálap-ho kstái sa ak'uás máltep aqás-ho kstái, ak’uás ak'uát kiarahák-ker-hójok sa? Talkskaláwa kæes at sa, Talkskaláwa kæes sa at er-k'éna ačáal hójok, kuosá sálta awóksor awahák-qeičéjer-hójok sa, lājep kupép jakákste aqahák-ker-hójok qeičéjer-hójok sa kupép. Jakákste táusa wa kuos lájek-s aqáksor.

Se sale [a remo] por el canal Picton, por ahí por ese canal se sale para ir a la costa exterior, ¿cómo lo llamaban? En el pase Talkskaláwa hay un campamento, el pase Talkskaláwa siempre era campamento, era punto de llegada para mariscar locos, por eso se alojaba ahí, es hermoso, también se llegaba ahí en tiempo de huevos. Sólo en tiempo de huevos se llegaba para buscar huevos.

(Aguilera-Tonko, 2009: 29)

El tipo de caza es diferente en la costa interior y la costa exterior. Esta división constituye las dos partes que conforman el territorio kawésqar: jáutok (interior) y málte (exterior) ${ }^{5}$ :

(2)

Jekčál kepás ak'uás kuo os kepás-er-k'éna málte jenák-k'enák-er-k'éna asó aqáse-ketæél so. Jautáuk ak'uás kiarlájer-s kuo kuos wa kiarsekčéjer-hójok kuos jekčál atæél-ho ka kuteké jekčál ksepjá-kejér wæes kuo. Jekčál léjes aqasekčéjer-hójok kuo kuosá asáqe léjes ku kiuk aqačál.

Yo no conocía los ciervos, no los imaginaba, ya que siempre anduve en el mar de la costa exterior y ahí navegaba siempre. En la costa interior que asíllaman, en cambio, como así se llama, es lugar de ciervos, y lugar donde andan ciervos. Se iba a cazar ciervos en embarcación y se los buscaba para comer y llegábamos ahí a remo.

(Aguilera-Tonko 2008a: T.SA-290307)

5 Para más detalles en cuanto al territorio, características y división, véase Tonko, 2008: 17-20 y Aguilera, 2008b: 51-53. 


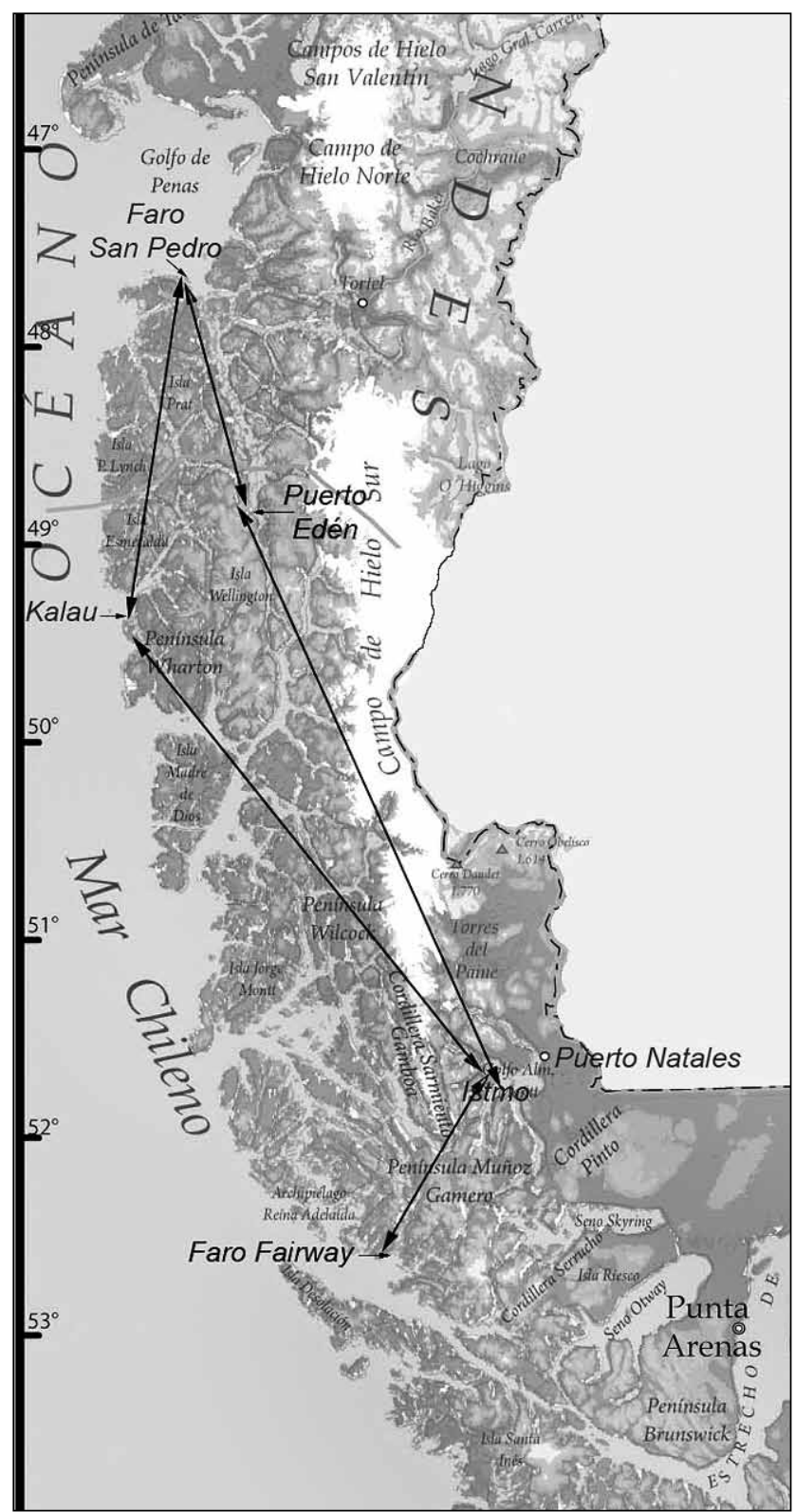

Fig. 1. Puntos de concurrencia habitual en las rutas de viaje kawésqar.

Los relatos de viaje registrados por nosotros (Aguilera-Tonko 2008a) abarcan el período comprendido aproximadamente desde 1940 hasta la actualidad; el presente trabajo se basa en relatos de los informantes Gabriela Paterito Caac y Raúl Edén Ulloa, que cubren el período de la niñez $y$ adolescencia de la primera $y$, del segundo, su período de adulto joven. Los relatos de Gabriela Paterito dan cuenta de períodos de nomadismo sólo de miembros del grupo étnico y luego en compañía de cazadores chilotes. Los relatos de Raúl Edén cubren la época en que ya se había establecido población chilota en Puerto Edén, la cual interactuaba con los kawésqar.

Para concluir esta presentación, citamos las palabras de Mateo Martinic, quien en pocas líneas retrata certeramente a este antiguo pueblo marítimo del extremo sur del continente americano: 
Los kawéskar eran genuinos hijos de las aguas y la bruma, habitantes de un territorio marítimo inclemente y rudo como pocos, aunque de salvaje generosidad, que imponía una movilidad permanente en la búsqueda de recursos para la subsistencia. La navegación era así la respuesta para un requerimiento esencial de su existencia nómada, técnica que dominaban con maestría incomparable empleando unas embarcaciones precarias y frágiles, pero eficaces para su objeto. (Martinic, 2004: 50)

\section{ESTRUCTURA DE LOS RELATOS DE VIAJE}

En forma general, los relatos de viaje kawésqar siguen el patrón usual de este tipo de narrativa: punto de partida ----> puntos de llegada intermedios ---> punto de llegada final. En el caso kawésqar es preciso considerar dos épocas en los viajes a través del territorio, que dicen relación con los períodos de pre- y post-asentamiento del grupo en Puerto Edén.

En el período pre-asentamiento el punto de partida puede ser cualquier lugar dentro del territorio, al igual que el punto de llegada; no necesariamente se trata de un viaje de ida y regreso al punto de partida, un roundtrip. Sin embargo había sitios de concurrencia habitual, que eran: (1) el faro en la isla San Pedro, en la parte norte del territorio, cercano al golfo de Penas; (2) Puerto Edén y cercanías, como Puerto Grappler; (3) la isla Kalau, en la zona del mar exterior (málte) y, (4) el sitio denominado Istmo, cercano a Puerto Natales. Podría agregarse a estos lugares el faro Fairway, como el extremo más al sur visitado por la última generación de navegantes, que actualmente está asentada en Puerto Edén.

El faro de la isla San Pedro tenía un carácter especial porque era un puesto de intercambio, un sitio donde se realizaban operaciones comerciales cuando florecía el comercio de pieles en los canales. Allí los kawésqar obtenían municiones para sus armas de fuego y víveres 'occidentales' a cambio de las pieles de nutria o lobo marino. Allí también se organizaban cuadrillas con chilotes o compuestas solamente por gente kawésqar para salir en viajes de caza (cf. Aguilera-Tonko, 2009: 13).

Puerto Edén antes del establecimiento de la base, era sitio de campamento temporal en distintos puntos de la bahía Edén (Jetarktétqal), pero se transformó gradualmente en sitio de permanencia habitual una vez que se instaló la base de la Fuerza Aérea allí. Sin embargo, los kawésqar no abandonaron completamente la vida nómade, como lo señala Emperaire: De vez en cuando, algunas familias abandonan, por períodos que llegan a abarcar varios meses, su aglomeración semiestable y, equipadas con provisiones cuidadosamente economizadas, vuelven a tomar la ruta de los canales para una expedición de caza. Durante este tiempo, utilizan los lugares tradicionales de campamento y, a pesar del pequeño número de los nómades actuales, el dédalo de los archipiélagos está aún jalonado por varios centenares de armazones de chozas. (Emperaire, 1963: 77). En el período post-asentamiento del grupo en Puerto Edén, el punto de partida y el punto de llegada final al regreso era Puerto Edén.

Kalau era el punto intermedio al occidente, escala obligatoria en los viajes por encontrarse en un entorno donde la caza y recolección estacional era abundante. Desde allí como campamento base, los kawésqar podían acceder a las loberías en tiempo de crías y a los lugares donde podían recolectar huevos y cazar aves en las temporadas respectivas. Por ello el sector de málte, i.e. hacia el Pacífico, era muy importante en los desplazamientos de la etnia.

\section{Punto de partida}

Como se señaló más arriba, el punto de partida podía originarse en cualquier lugar del territorio antes de que los kawésqar se asentaran en Puerto Edén. Por ejemplo, el relato T.SA-290307, (Aguilera-Tonko, 2008a), se inicia en Kalau:

Kialáu kte asé awesekuéjer-hójok ko-ásek čečél-k'enák jekčál akskuokéjen-čejér sos kuo c'errás ka kuteké jet'ás-jerák kius káwes askét... kstejékians c'e... jek ... kčejertqána-kesektálæerhójok, kesektálæer-hójok k'ejeháker-hójok kiuk. (.....)Ko ásek čečél so kutálap aqájeks.

Alojé en la bahía de Kalau, en esa bahía estuve varios días, los ciervos que se habían tirado al agua los trozamos y comimos, sus pieles este que... les sacamos cor ... sec ... quedaron puestas a secar en el bastidor ahí (.....) Después de haber permanecido en esa bahía proseguimos el viaje. 
En los relatos de viaje kawésqar el esquema general es el siguiente:

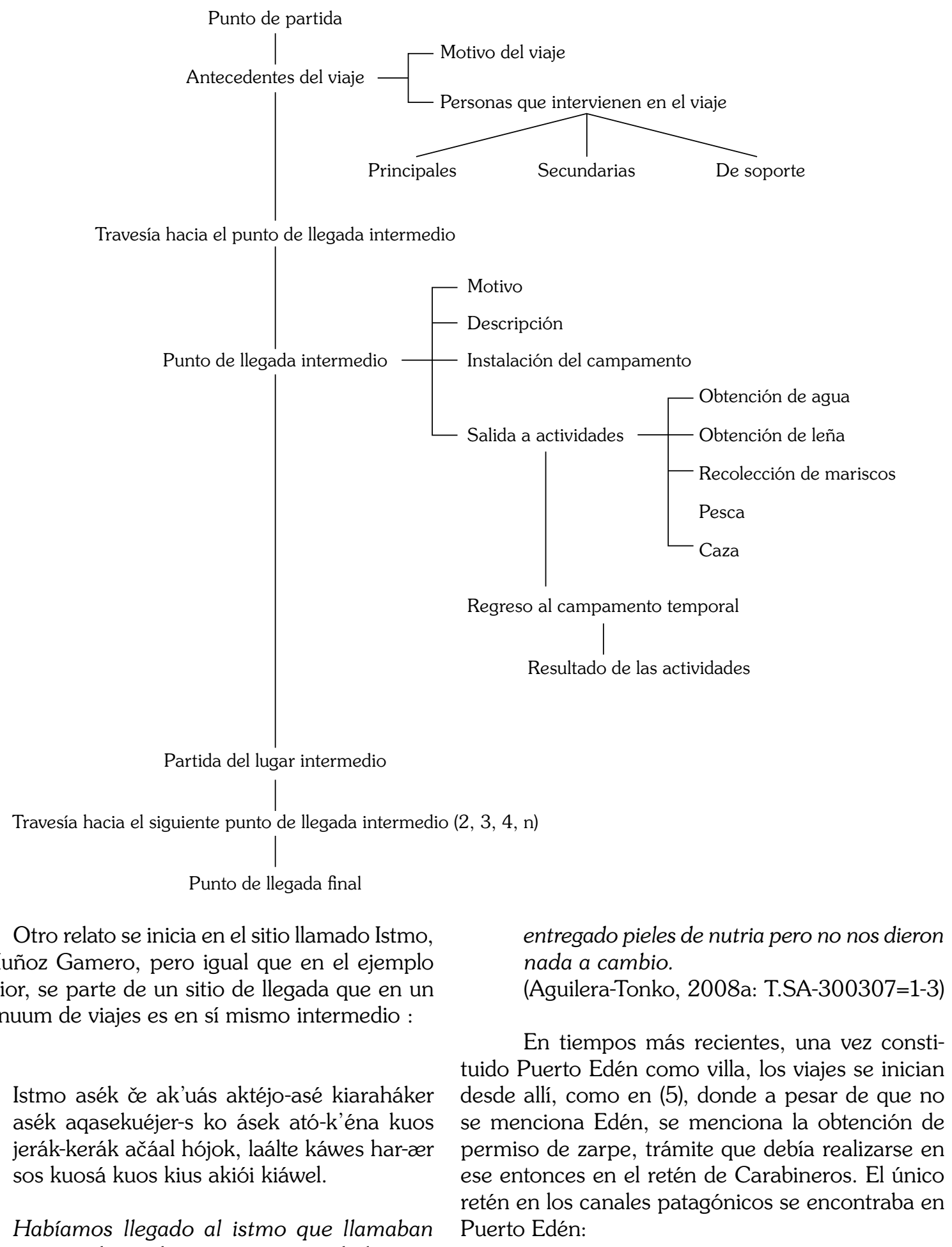
arrastradero, ahí permanecimos, habíamos 
(5)

Jenák asós eit'ákos kuos aqájeks kupép k'exás čečáu-čepatók jenák asó kuosá retén tæel ačáal ko álowep ka kuos zarpe-k'enák-s jenák; eit'áksta táusa jepsórk jenák asó sa kuos k'exás eit'ákos aqájeks.

Después de haber estado [en esa casa] cuando vio que había calma, zarpamos por último, ya que teníamos todas las cosas embarcadas y en el retén que estaba ahí, en él sacábamos zarpe; estábamos esperando calma y por último al haber calma zarpamos.

(Aguilera-Tonko, 2008a: T-SA-140407=2)

Motivo del viaje

El motivo del viaje en los tiempos antiguos era la caza de subsistencia; con la incorporación de loberos y nutrieros en el territorio kawésqar, la motivación seguía siendo la caza, pero para la obtención de pieles que comercializaban, trocándolas por alimentos, vestuario, armas y utensilios ${ }^{6}$. Posteriormente las salidas eran para trabajar en la obtención de cholgas, ya sea como miembros de una cuadrilla de chilotes o bien sólo kawésqar para vender posteriormente el producto a comerciantes chilotes o venidos de otras partes del país. En los relatos de tiempos más recientes, los viajes son por motivos de salud o trámites que deben realizar en la ciudad.

(6)

Če sa jerk'éperk tawaisélok ksersekuás-erhójok séjep æes k'iápæer jepæés asé ka kuteké čekéja léjes asé.

A mí me llevó mi hermano invitada para ir hacia al sur a cazar pájaros con lazo y también lobos.

(Aguilera-Tonko 2008a: T-PE-MIT-011206)

(7)

Serró-jeké sa čeihéna lafk asó kuos jerwosekiólæer. Kuosá ksenhánno aqásek jerwolájer-s k’iak. Jaláu jenák asó čečáu-jetáktas jeksólok

6 También como producto del trueque los kawésqar recibían licor, que estaba -por así decirlo- "dentro del paquete" de posibles cosas que podían recibir a cambio. jenák asós kuosá wæes táu hápar aqájeks čepás jenák kuos. Laálte jektálk jerwaháker asó sa kupép čečáu-jetáktas Tite Mayorga kiaraháker sa kuos jenák ku fsek kuos Montón. Kučelák álnak ka kuteké kius laálte káwes čelkosék'ejésap jenák ačáal hójok.

La chalupita que habían construido recientemente la ofreció, [la chalupa] que estaba fondeada. Y mandó que la llevara inmediatamente. En ese entonces estando [ahí] se entusiasmó el finado [Samalo], que estaba [ahí] y estaba pensando en zarpar a otra parte. Y lo había mandado a cazar nutrias al haberlo propuesto también el que llamaban Tite Mayorga, que estaba en ese lugar y [también] Montón. Trabajaban juntos y era el que llevaba los cueros de nutria navegando [a Punta Arenas].

(Aguilera-Tonko 2008a: T-SA-140407=2)

(8)

Levicán ko ásek čejá aqátæel kuos kiot kučelák aqátæl-k'ejétal sos čeá. Kuosk'á séwel kuktép čečáu-jeqolókna sa kuos kserlájer akčáwe c'elásna-k'éjes kius k'exátau, kuosá æes qolóknas jenák kuo lafk ko ásek asá-k'ejétal-s. Kiut k'exátau k'exá qei so ker sa, akčáwe c'elásnak'éjes ksernzésk jetátal kuos čeá čes ko ásep asér. Čeá kst'apón ka kuteké kserlájer-s kuo kuos asá-k'ejétal-hójok-s jenák, kuos čeá ko ásep asá-s kuos.

Andaba yo con Levicán y finalmente siempre andaba con él yo. Sin embargo, yo lo conocía cuando me solicitó últimamente para trabajar en la cholga seca, ya lo conocía, ahora embarcado andaba siempre. Por último habría de ser la última vez, estaba solicitándome para secar cholgas y yo me embarqué con él. Cuando los chilotes me solicitaban siempre yo iba con ellos, y me embarqué con él.

(Aguilera-Tonko 2008a: T-SA-120407=1)

Personas que intervienen en el viaje

Las personas que conforman el grupo de viaje algunas veces son presentadas al inicio del relato; 
por lo general, aparte del narrador, sólo aparecen los personajes principales o bien personajes que son importantes para la etapa inicial del viaje que se narra, es decir, personajes de soporte o auxiliares, como por ejemplo, el dueño de una embarcación que facilita ésta a la cuadrilla que hará el viaje; en este grupo también se encuentran autoridades que otorgan los permisos (permiso de zarpe) para iniciar el viaje. Asimismo se encuentran aquellas personas que sirven de referencia para la identificación de un personaje principal, por ejemplo, el personaje principal $\mathrm{X}$, hijo de $\mathrm{Y}$, en donde $\mathrm{Y}$ es un personaje de soporte. En algunas ocasiones a lo largo del relato se transforman en personajes que tienen una intervención menor, lo que les otorga un carácter de mayor relevancia que los personajes de soporte; son personajes que denomino secundarios. En (9), por ejemplo, el personaje Peyáu que aparece al final de la cita, se transforma en personaje principal más adelante en el relato. En (10) Queimán es un personaje de soporte, es uno de los tantos chilotes que intervienen en esa narración; por otro lado, sirve de identificador para el hijo, quien aparece después en el relato.

Jektæél jetæél-s kuos woks, tarrés kájef asé: Kiárlos kájef ak’uás kius kájef jetæél ačáal hójok sa kius čačár ka kuteké c'ap asé jetzél sa jetál. Tóu asék jetzél-s jetzél askét jeksólok tawaisélok askét... Petéjen-s kéwes tawaisélok ak'uás apánap tawaisélok jetzel, Petéjen tariép če ... ajáu Petéjen tawaisélok čačár kuteké c'ap tawaisélok Petéjen-jeké sa sa jetzél ačáal hójok-s. Kius taksóktek-sélas tawaisélok sa kawésqarsélas fsetqaná ak'uás fséja hoikuolzésna jetzél ačáal hójok kuo k’iak. Kiáf so kius jerképerk tawaisélok ka kuteké antáu kuos čappačéwel kius jeksólok kius taksóktek jetzél ačáal atál hójok. Pejáu tawaisélok sa æes ko-áse jetál jetæél-hójok kuosá kius aihiól tawaisélok arhána ka kuteké Pascual wa kiarsektálær-hójok kius afterrék aihiól arhána-s kuos.

Andaba de caza, eran dos, tres embarcaciones: la embarcación de Carlos, su embarcación andaba, su papá y su mamá andaban embarcados. En otra embarcación andaban este que ... los finados este que... andaba la finada abuela materna de Petéyen y su finado abuelo paterno, Petéyen miento ... sí el papá del finado Petéyen y también su finada mamá y andaba ahí Petéyen muy pequeñito. Su finada hermana era adolescente y mujer grande y andaba igual. También su finado hermano y todos estaban vivos, ahí andaban los hermanos del finado. El finado Peyáu andaba en mi embarcación y su finado hijo adulto que se llamaba Pascual y era su hijo mayor, adulto.

(Aguilera-Tonko 2008a: T.SA-290307)

Istmo asék če ak'uás aktéjo-asé kiaraháker asék aqasekuéjer-s ko ásek ató-k'éna kuos jerák-kerák ačáal hójok, laálte káwes har-æer sos kuosá kuos kius akiói kiáwel. Kimán tawaisélok séjep kukté-terrék Kaméro-ktek palo ken... Kaméro-kte kúkta séjep ko áse, C'ána-kérwa ak'uás kiaraháker álowe k'oláf. Separrés kenčás jenák-kečé k'iújef alhói-hójok kiafáro wa kuos asáqe léjes aqahójer, kius at páu kæes tqal akér awál čečél-s kok. Kius at páu kæes tqal akér ra awák, jekuá. At páu kæes awál jerwosé-ker kuos at aksó-hanná ak'uás alhánæer. Har hápar asá-kečé so jenák ačáal hójok atói kius sejóra askét... Natálep aqáče, Natálep asáqe léjes ka kuteké t’asénska léjes aqáče.

Habíamos llegado al istmo que llamaban arrastradero, ahí permanecimos, habíamos entregado pieles de nutria pero no nos dieron nada a cambio. El difunto Queimán estaba más al sur de [Muñoz] Gamero cort... palos, en la bahía de más al sur de [Muñoz] Gamero, adentro en la playa que se llama C'ána-kérwa. Había estado cortando cipreses, mientras tanto llegamos y de un momento a otro llegó él a buscar víveres, cuando estábamos alojados al lado de su casa. Alojamos al lado de su rancho, oye. Nos ofreció que levantáramos la carpa junto al rancho y la armamos. Hacia el interior [del seno] se había ido [él], habría estado [sola] su señora este que... se fue a Natales, se fue a Natales a buscar víveres y también a buscar harina. (Aguilera-Tonko 2008a: T.SA-300307=1-3) 
Travesía hacia el punto de llegada intermedio

El viaje hacia el punto de llegada intermedio se desarrolla en la narración cuando hay un evento importante que relatar o un antecedente que sirve para destacar, por ejemplo, las dificultades de la navegación a través de la ruta, o bien para describir brevemente la ruta hasta la llegada al punto donde se establecerá el campamento, como en el siguiente ejemplo:

Hóutsap álowe ka kuos alíkar-s qal-eihén kuosá næes aqátal kuos kstái lejésap ka kuteké wæs qólok kuo ouseræér kupép jemmá arhána, ku kiáu wæes kte ku jennák aqátal. Af aqál-k’éjes kuos asahák-er. Kep-s hóutsap álowe-terrék čečél-s. Wæes jáu aksér čerwás-kečéjer kuosá kuos málte jennák hójok eihén-akstá-ar alíkar kuos aqál-eihén-atál kuo-aksék. Seté kstái atálterrék ka kuos kstái hájes af aqál-k'éjes qué jat-s k'ak hajés k'élok kar pe čečél jeksórk tæes kuerwolái-akstá-kečéjer. Kuosá næes aqának kuos wæes qólok ka kuteké hajés qólok kupép, če sa ouskseræér-s jenák-hójok.

Hacia el mar de más afuera hay muchos roqueríos donde revientan las olas y él siempre remaba en la proa, era el que veía la ruta y conocía esos lugares y sabía bien esa parte, también era un blanco viejo, siempre había navegado por esos lugares. Me decía que en la entrada había rompientes. Más afuera no había nada. Los lugares que estaban hacia la costa eran apenas visibles, esa puntilla era del mar exterior y todavía estará ahí, hay bajos con rompientes, por eso hay olas. Hacia el sur hay un canal cuya entrada tiene rompientes que en un momento no tiene olas ahí y cuando se ven con [los propios] ojos había que decidir [si se avanzaba]. Y él estaba remando en la proa porque conocía el lugar y también conocía las olas, yo estaba consciente de eso.

(Aguilera-Tonko, 2009: 96)

Punto de llegada intermedio

Los puntos de llegada intermedios constituyen por lo general episodios importantes dentro de los relatos de viaje. La navegación en sí no contiene episodios relevantes. Esto se debe principalmente porque para los kawésqar es importantísima la navegación segura y por ello prestan mucha atención a las condiciones climáticas. Son escasos los episodios de realce en medio de la navegación, más bien son descriptivos y dan a conocer la ruta. En cambio en los puntos de llegada intermedios se desarrolla la vida en el campamento donde pueden ocurrir situaciones de diversa índole. Es un punto de reunión de las cuadrillas, tanto de la que forma parte el narrador como de otras que llegan o se encuentran ya instaladas. Es el sitio donde se organizan y planifican las partidas de caza, pesca, recolección, obtención de agua, leña, donde ocurren incidentes, etc.:

Akiúk asós? Akiúk ak'uás aqak'énar... aqačálhójok-aká? Tawók-takiér-jowá-jerás kiarahák-er jerás ka. Kiúka Owánto tawaisélok aqak'enáker kokiúk Pérro tawaisélok. C'apáne ak'uás kiarlájer sa ko ásep čečél ačáal kius jémo-op, kuosá Rosa Arlái tawaisélok kuos ko áse jerák ačáal kius cocinera, terrés jetæél-s.

¿Dónde fue eso? ¿Adónde nos encontramos... llegamos? Se llamaba Tawók-takiér-jowájerás, era un terreno en pendiente. Ahí nos encontramos con el finado Ovando ahí, el finado Pedro [Ovando]. Como su remero estaba el que llamaba C'apáne, y en esa embarcación estaba la finada Rosa Grande, su cocinera, andaban tres.

(Aguilera-Tonko, 2008a: T.SA-310307=1-2)

Jálau jeksólok ak’uás Guarello kernár jenák asós čenčón t'ak tæl-atæél hápar čečáu-... woks čečáu-afsé-kepásna ak'uás os-kepásna kek'ojóna pep, čenčón atzélp kaftálkqar-jeké ketálk jenák so t’akiár kiújes-ker, æesk'ák. Pap pap! Kaftálqar éjok t’akiér.

Jeksólok ak’uás kius kučelákso kučelák jenákatál asós čečáu-jefte... akc'ólai léjes-kečéjer kuosá kaftálqar awáqas k'élok ak'uás hójok ās, kuosá kaftálqar éjok táusa t'ak'iáqas kuósos ko-aswálak kawéra k’enák annának ke! 
Kuos čečáu-jertónæer tæl tot ak'uás t’ak'ár-er sos, čenčón k'uák'iák jenák asós sa. Kuosá kaftálqar awána awa... awáqas k'élok. Jeksólok-sélas tóu tæes pe qólok jerák kiut akuoksqans-er-s kuos. Čenčón jerkiórk jenák asó sa. Ke kuos čafarák! Kuósos ko-aswálak ka kuos jerák čepákser annaháker

Entonces el finado que habría de ser enterrado en Guarello hacia el chonchón que estaba encendido... cuando los dos estaban entretenidos en la conversación y se le había olvidado por la borrachera, inclinó la cabeza hacia el chonchón y se incendió su cabellera y salieron llamas, así. ¡Cielos! Ardió su cabellera.

Los finados que eran sus amigos y estaban con él se asustaron y fueron a buscar agua y no se quemó la cabeza, y sólo se le quemaron los cabellos y al otro día estaba blanqueando y se reían, juaya cosa!

Y estaba enojado porque otros lo habían incendiado, pero había estado cerca del chonchón. Y no se quemó la cabeza. La otra finada que estaba sobria, ella lo apagó. Había estado cerca del conchón. ¡Claro, pues estaba bebiendo! Y al otro día ahí estaba y cuando se acordó se rió.

(Aguilera-Tonko, 2008a: T.SA-300307=1-3)

La motivación de navegar hacia un punto determinado, antes de que los kawésqar comenzaran a trabajar junto a los chilotes en la extracción de mariscos, siempre es la caza, ya sea para aprovisionarse de comida o para obtener pieles. Los relatos ilustran las diferentes técnicas utilizadas, como por ejemplo, uso de redes loberas, arpones, escopetas o caza de aves al acecho. En el siguiente ejemplo se menciona la técnica de "esperar pájaros", para cazarlos mediante un lazo llamado tánqe:

Háute æes-kstái asér sos čejá kuos Kskaift'əésastál aqasekué awál ačéjer háu at sétqa háute ku c'éwe akér sétqa kuo aksál tæel-s ku jepæés ka kuo ranchero ak'uás kiaraháker ku jepzés. Jepæés awál awóksa ak'uás eit'áksta awál árkap har tqal siafk' iás herkolájer-s kok ak'uás čeppačéwel táu če čečélk aswál hójok?.

Después de haberme embarcado aquí al frente, llegamos al itsmo de Kskait'zes, ahí alojamos al frente de un paraje de pájaros ${ }^{7}$ que es barrancoso, a esperar en el paraje de pájaros que se encuentra en altura, a esperar en el barranco del ranchero que así lo llamaban. Alojamos para cazar pájaros e iniciamos un nuevo campamento, acampamos cuando había calma chicha en un lugar al que llega viento de frente, ¿si soplara viento, acaso íbamos a amanecer sanos y salvos?

(Aguilera-Tonko, 2008a: T.PE-MIT-011206)

En los relatos también siempre se comentan los resultados de las partidas de caza, sean éstos positivos o negativos; el motivo de la evaluación de la caza es recurrente en todos los relatos:

Páu jénnak táu kukték čečél so jerfelái-ker; Kskaláute sa kuos jewonáræer atæel ho ak'uás ček... jekčál asó jetafténa lafk kúkta asós kuos alái kotéjo čekék-k'eqáqa léjes ka kuosá kep-s jewonáræer. Kep-s ko-ásek čečél, ko-aswálak k'iápæer jerfelái-ker čečáu-jewónær.

Después de haber estado en la puntilla de más afuera, zarpamos; Kskaláute es un paraje de ciervos, pero no encontramos nada, los ciervos que ahí se encontraban se habían asustado por nuestra reciente cacería y fuimos a mirar si habían bajado de nuevo, pero no encontramos nada. No había nada en la bahía donde estuvimos, al día siguiente inmediatamente zarpamos [porque] no encontramos nada.

(Aguilera-Tonko, 2008a: T.SA-290307)

Kútqal kčepkékskol kuos wæes hápar āsker kiúrro táwon, kuosá tejekástat táusa léjes kuosk'á séwel čálaka kájef asé koáček. Tejekástat táusa ksepsór ra ker jelái-er so

i.e. de cormoranes. 
kuos jetákar. Kuktép jenák jewólna-ker kuos kselaháker-atál c'afaláitqal wa jetahák-hójok kútqalk. Kuosá gancho kčeihéna táwon kuos atakiáræes lálætal so čerhapéna-k'ejehák kstal-s jetaháker-hójok kútqalk, kuosá jetákar ksqáwer woks kskoqáqar. Kiúrro-s kuos tesákos tæelamás eikuofténa tesákos-er kuos akuačejér-s kútqal jenák. Pána táwon kuos jenáker kuosá asáqe léjes, jenák jewólnæer kuosá kius kiúrro jenák ačáal kiut jetakénæerk.

En ese estero fondeamos y fuimos caminando por tierra con los perros, y sólo andábamos buscando coipos, sin embargo la escopeta la dejamos en la embarcación. Sólo encontramos coipos, nos aprovisionamos con aquello que fuimos a buscar. Trabajando en ello nos sorprendió la tarde y los perros les ladraban y estábamos cazando ahí en una laguna. $Y$ con un gancho que habíamos fabricado gancheamos los que se habían tirado al agua y que andaban nadando, eran muchos los que cazamos ahí, cazamos hartos [y] los amarramos en dos atados. Llamamos a los perros y por último los asustamos golpeándolos y los llamamos; los [otros coipos] que estaban ahí los dejamos. Estábamos muy contentos y andábamos cazando comida, y así pasamos la tarde y además los perros nos retuvieron.

(Aguilera-Tonko, 2008a: T.SA-140407=2)

De esta manera se suceden las partidas y llegadas a los lugares intermedios hasta alcanzar la meta final. Como se dijo más arriba, los lugares intermedios contienen eventos importantes dentro de los viajes; sin embargo, en ocasiones algún lugar sólo se registra como punto de llegada, sin mayores detalles, como parte de la travesía. Los relatos de viaje concluyen en general con la enunciación de otro viaje, siguiendo así el constante ciclo de nomadismo de los kawésqar; en otras ocasiones un evento importante producido en el punto de llegada final constituye el cierre del relato:

K'exás kúkstaik kuósos aqahói ka kuos čečélk'enák. Kuo če kotéjo aqájeks. Kupép æes kájef čowá jetæél ačáal hójok. Kájef ak'uás jeksólok tawaisélok-s kájef. Kájef-jeké lájep ačáal hójok sa kius kenčéso-jeké, paks-jeké kuo aksék halhájer-jeké-hójok sa aqáwes ak’uás atáuk k'élok jeké.

Finalmente llegamos a ese lugar y ahí siempre permanecimos. Yo zarpé nuevamente. $Y$ también andaba en mi canoa. ${ }^{8}$ La canoa era del finado y difunto, [su] canoa. Linda canoíta, él la había fabricado, era liviana, por eso nos gustaba, [era] estrecha y no se llenaba de agua.

(Aguilera-Tonko, 2008a: T.PE-MIT-011206)

Kiúrro jetæél so ankstás kuosá kius jeksór paks čo erk'éna ačé-s kius ksépsos kuos, t'óustqal ksepsós ankstalájer kuosá kselájer ku ástal tæel. Taqálkte ko ástal-terrép atakiáræes woksterré astál k'uák'iak astál čečél-s kuos. Háuterrék čo lói-kečé so, apáik aqákiar, kupép terwá woksterrék har-asé-terrék čejá kekiáser. Jetákos atakáræes lalðénak ačáal. Kukték Juanero-s čelkohójer-hójok-s kuos. Kuosá Juanero-s kuo qark ku táwon jetæél kuos čowá askét... akue-sekuéjer čóčo; æes ku kiáu čelkuestál so sa æes jefése k'élok jetæél so. Kuosá teselájer-s kuos kius k'ápæer k'oának har chuico sa kius akiói tesaháker.

— Tóu-s qar-sekué jat — zesk'ák kuos asénak.

Kuosá kuos attás kuos har kuos tóu asé-terép hark akiár. Jetá-ospenáræer čejá hatalájer jeksórk. Kuosá kiut asahák-er so kuos, kuos kās tóu-s jeksór-s k'iak k'iápær. Woks jekčál qar-nar. Kuosá æes aqahói aswál sepplás-ker k’ak kuos čeá asenák:

- Aswálak čeá aqahói-sekué háutep.

Herkuok'énærk ku fsek čečél ačálnar. Kuosá eit'akos aqahói kuosá sepplaktá k'élok kuos tælamás ka kuteké ft'ói jetátæl asó kuokčé ko-ačéjer-hójok woks jekčál táwon. Levicán-s k'ápæer har-hójok kius k'iótpek askét... ku táwon ālktæes ka kuos jerwónak jewá hójok. Ku ktep

8 Ironía. 
jetanák-s kuos. Afčár asé kénnær čowá kius kájef tesahák jewá hójok kep teselái k'élok.

El perro que andaba olfateó y yo identifico rápido sus huellas (i.e. de los ciervos), las huellas de las pezuñas olfateó y ladró y ahí estaban en ese istmo [los ciervos]. Se lanzaron al agua al otro lado del istmo, ambos lados es cerca. Por fuera yo llegué, lo rodeé rápidamente; también [remaba] con ambas manos, [antes] había bajado corriendo más al fondo del estero. [El perro] los había hecho lanzarse al agua y ahí estaban nadando. En ese momento llegó [el chilote] Juanero. Y Juanero lo mató y andaba con él (i.e. el ciervo) y yo este que... lo llamé haciéndole señas para que viniera hacia mí; [antes] había pasado de largo cerca [de mí] y no me quiso remolcar. Y me pidió que se lo diera todo a él a cambio de un chuico [de vino].

- Vas a matar otro al rato-así dijo.

Yo estaba enojado y tomé [el ciervo] y lo lancé a la otra embarcación (i.e. la suya). Me hizo encolerizar al ver que me lo estaba disputando. Y como él había dicho, igual encontré otro inmediatamente. Habría de matar dos ciervos. Y me preguntó qué día iba a llegar y yo le dije:

- Mañana llegaré al otro lado.

Y habría de estar ahí retenido por el viento. Y con calma chicha llegué, no me preguntó por haberse portado mezquino ${ }^{9}$ conmigo, por eso me dejó con dos ciervos. La parte trasera se la di a Levicán, este que... por el hecho de haberla recibido siempre me ofrecía [algo]. Y ahí estaba comiéndola. Para ir a la leña yo siempre le pedía la embarcación y no se la pedía así no más [para otra cosa].

(Aguilera-Tonko, 2008a: T.SA-120407)

9 "Mezquino" porque no lo quiso remolcar. Si lo hubiera hecho habría recibido parte de la caza en reciprocidad por el transporte. La usanza kawésqar consiste en ser recíproco por algo recibido.
En (18) el narrador cierra su relato con un evento en donde el punto de climax está en la disputa por el ciervo muerto. El narrador había realizado la caza con su perro y el chilote Jovino quiso aprovecharse, dando muerte al ciervo que estaba en el agua tras la cacería iniciada por el narrador. También pone de relieve el hecho de que no quiso remolcarlo anteriormente. Como la presa pertenece al narrador, el chilote intenta hacerle un trueque por vino, pero no es aceptado. Posteriormente le da parte de la presa a otro chilote, Levicán, con quien había realizado el viaje que ha narrado. El autor contrapone la conducta de ambos chilotes, el que quiere aprovecharse de él y del otro que había sido bondadoso y le enseñaba. Por ello comparte su caza con este último y concluye así su relato.

\section{LA REFERENCIA DE PERSONAS EN LOS RELATOS DE VIAJE}

En esta sección se examinará la referencia a personas tomando en cuenta la distancia referencial y las dificultades para establecer la referencia correcta en los casos que se señalarán.

En muchas ocasiones la referencia de los participantes en las narraciones kawésqar es difícil de seguir. Para el no hablante de la lengua resulta enigmático determinar cuál es el participante en la narración al cual se refiere el hablante en los siguientes casos: (1) la referencia apunta a factores culturales (es propio que la persona referida sea quien ejecute ciertas tareas o funciones específicas dentro del grupo que son muy claras para los miembros del mismo y, por lo tanto, no es necesario nombrarla); (2) en ocasiones la distancia referencial es grande y se remonta a varias oraciones anteriores; (3) el poco uso de pronombres; (4) el uso abundante de referencia $\varnothing$ (referencia nula $)^{10}$; (5) la falta de diferenciación de género en las formas pronominales produce "interferencia" en la localización del referido cuando se combina con (1) y (2); (6) la no inclusión de un

10 En donde no se nombra a la persona referida y en la oración no hay un pronombre o sustantivo sujeto (u objeto) y sólo se puede determinar el referente por el contexto, o bien se trata de oraciones impersonales o de sujeto indeterminado que puede remitir a un "ellos" implícito, parecido al inglés en casos como "they say...." dicen...., aunque en inglés el uso del pronombre es obligatorio. 
pluralizador verbal optativo que puede hacer ambiguo el número y (7) error del narrador al no especificar claramente la referencia, esto debido a que hizo un paréntesis en la narración a fin de describir algo y luego retomó la narración aludiendo a una persona mencionada antes, pero cuya distancia referencial se hizo extensa, sin percatarse de este hecho.

A pesar de las interferencias en la determinación de la referencia en kawésqar, es posible observar ciertos patrones que ayudan a resolver el problema.

\section{Distancia referencial en la} determinación de la referencia

Al tomar en cuenta los parámetros de (a) menor distancia referencial (DR-) y (b) mayor distancia referencial (DR+) (cf. Givón, 1983), en kawésqar se aprecia lo siguiente:

(17)
DR- : referencia $\varnothing$, un pronombre

$\mathrm{DR}+$ : un sustantivo, frase nominal

Un participante puede ser introducido por un nombre propio, un sustantivo o una frase nominal, como por ejemplo:

Takérra $=$ nombre propio

jeksólok = el difunto

Patricia-s k'éwe-sélas = la abuela materna de Patricia

Petéjen čačár tawaisélok = el difunto padre de Petéyen

Si el sujeto o no sujeto ${ }^{11}$ sigue siendo el mismo que en la oración anterior, la referencia es $\varnothing$ en la siguiente oración y subsiguientes, como en el ejemplo que sigue, donde el número entre corchetes sirve para identificar a la persona:

\section{æes-kstái}

aquí

jenák-k'enák-hójok

ser/estar-HAB-PRET.NARR

Takérra [1] siempre estaba aquí al otro lado.

$\varnothing$ [1] tawókser

tawókser $=$ kawésqar del sur

$\varnothing$ [1] tawókser [era]. [jenák-k'enák-hójok] ${ }^{12}$

[ser/estar-HAB-PRET.NARR]
kius [1]
ktæl
sa
kuos
jemmáu
$\varnothing$ [1] kiárksta
Alesantri
su [1] nombre
PP.TOP CONECT
hombre blanco llamar ANTROPON

su [1] nombre, como los blancos $\varnothing$ [1] [= a él] llamaban, era Alessandri.

(Aguilera-Tonko, 2008a: T.PE-MIT-011206)

Tras el uso de $\varnothing$, el hablante puede considerar que la DR es amplia, por lo tanto reintroduce a la persona referida mediante un apelativo identificador. No obstante la DR es variable ${ }^{13}$, puede abarcar un buen número de oraciones o ser menor y sin em- bargo producirse una reactivación de la referencia mediante el apelativo. Por ejemplo, en la oración que sigue a la última del ejemplo anterior, Takérra es identificado como jeksólok = el finado:

11 Puede tratarse, por ejemplo, de un objeto directo.

12 El verbo jenák ser/estar generalmente se elide, por ello aparece entre corchetes en el ejemplo.

13 Givón en su nueva versión sobre la DR de 1994 hace una distinción ternaria de la distancia referencial: 1, 2 ó 3 y más de 3. Sin embargo esta distinción ha sido criticada por diversos autores, quienes argumentan que la DR debe ser establecida tanto para una lengua en particular como a través de las lenguas y esto no puede hacerse si se realizan decisones a priori acerca de qué categorías de distancia se utilizarán (cf. Stanley, 2007). 
(18)
Jenák-k'enák-er
jeksólok [1]
ser/estar-HAB-DUR
finado

[Ahí] siempre estaba el finado [1].

\begin{tabular}{|c|c|c|c|}
\hline $\begin{array}{l}\varnothing[1] \text { æerk'uólæes } \\
\text { que no puede crecer más }\end{array}$ & $\begin{array}{l}\text { ak'uás } \\
\text { pues }\end{array}$ & $\begin{array}{l}\varnothing[1] \text { qak-s } \\
\text { pequeño-GEN }\end{array}$ & $\begin{array}{l}\text { k'eá } \\
\text { = k'ak } \\
\text { igualmente }\end{array}$ \\
\hline
\end{tabular}

$\varnothing$ [1] [Era] alguien que no podía crecer más, pues [1] era igualmente pequeño.
$\varnothing[1]$ toutápse-kual
[jenák-hójok]
ka kuteké
calumniador
[ser/estar-PRET.NARR]
como también

$\varnothing$ [1] [Era] calumniador como también

\begin{tabular}{|c|c|c|}
\hline $\begin{array}{l}\varnothing[1] \text { afkstái } \\
\text { boca }\end{array}$ & $\begin{array}{l}\text { arlái } \\
\text { grande }\end{array}$ & $\begin{array}{l}\text { [jenák-hójok] } \\
\text { [ser/estar-PRET.NARR] }\end{array}$ \\
\hline
\end{tabular}

$\varnothing$ [1] [era] bocón y

$\begin{array}{lllll}\text { tariép } & \varnothing[1] \text { asźétal } & \varnothing[1] \text { asénak } & \varnothing[1] \text { ječernák-ap } & \text { [jenák-hójok] } \\ \text { mentira } & \text { decir } & \text { estar diciendo } & \text { señalador } & \text { [ser/estar-PRET. NARR] }\end{array}$

mentiras $\varnothing$ [1] decía, $\varnothing$ [1] estaba diciendo [siempre], $\varnothing$ [1] señalador ${ }^{14}$ [era].

(Aguilera-Tonko, 2008a: T.PE-MIT-011206)

Si un participante tiene un rol protagónico, ya sea durante todo el relato o una sección importante de él, a pesar de que existan discontinuidades en el relato, por ejemplo, paréntesis introducidos por el narrador, la referencia sigue rigiendo para este participante, a pesar de que la DR sea amplia.

En el ejemplo siguiente el participante principal es Peyáu [1] y aparecen como participantes de soporte jeksólok [2] (= los finados kawésqar) y Carlos [3], que son presentados en un paréntesis cuya función es introducir el recurso retórico de la ironía.
La DR en este caso no es muy amplia, pero como el participante Carlos [3] es introducido al final, se podría pensar que todas las referencias $\varnothing$ que siguen remiten a él. No obstante la narradora repite en el segmento 142 la misma oración de la cual Peyáu [1] es sujeto en el segmento 136 (aqájeks mano woksterrék = zarpó remando con ambas manos), además de hacer referencia a una acción realizada antes por el mismo participante (salida a buscar lobos), con lo cual la referencia debería ser clara; al menos lo es para el oyente kawésqar: ${ }^{15}$

\begin{tabular}{llllll}
$\begin{array}{l}\text { 136. Pejáu } \\
\text { ANTROPON }\end{array}$ & \multicolumn{2}{c}{$\begin{array}{l}\text { tawaisélok [1] } \\
\text { finado }\end{array}$} & $\begin{array}{l}\text { kuos } \\
\text { CONECT }\end{array}$ & $\begin{array}{l}\text { kájef } \\
\text { canoa }\end{array}$ & ákstap \\
botar al agua
\end{tabular}

14 i.e. señalaba con el dedo a alguien cuando calumniaba o inculpaba.

15 Los números al comienzo corresponden a los enunciados de la narradora en el texto kawésqar. 
136. El finado Peyáu [1] se fue remando con ambas manos en su canoa recién botada, jvaya!

$\begin{array}{llll}\text { 137. Ko } & \begin{array}{l}\text { ásep } \\ \text { áse-p }\end{array} & \text { jeksólok [2] }{ }^{16} & \begin{array}{l}\text { asá-kekéjen-ačéjer-atál } \\ \text { asá-kekéjen-ačé-er-atál }\end{array} \\ \text { DET } & \text { finado } & \begin{array}{l}\text { embarcarse-correr.hacia. } \\ \text { el.interior-TRASL-DUR-PL }\end{array} \\ \begin{array}{lll}\text { kius [2] } \\ \text { para ellos }\end{array} & \begin{array}{l}\text { aqapáksna } \\ \text { aqás-paks-na } \\ \text { remar-liviano-PRTC }\end{array} & \begin{array}{l}\text { kXá } \\ \text { EXCLAM }\end{array} & \begin{array}{l}\text { Kiálo [2] } \\ \text { ANTROPON }\end{array} \\ \text { kuo } & \text { fsek } & \text { kuos } & \text { jerák } \\ \text { DET } & \text { fse-k } & \text { cONECT } & \end{array}$

137. En ella se embarcaron todos los finados [2] para que pudieran ellos [2] remar con menos esfuerzo [IRONÍA] y Carlos [3] estaba en el campamento,

$\begin{array}{lllll}\text { 138. feičétqal } & \text { ka } & \varnothing[3] \text { sekuás-er-hójok } & \text { ket } & \text { kiaráu } \\ \text { red } & \text { como } & \text { bajar-DUR-PRET.NARR } & \text { REFORZ } & \text { también }\end{array}$

138. también $\varnothing$ [3] salió con su red. [IRONÍA]

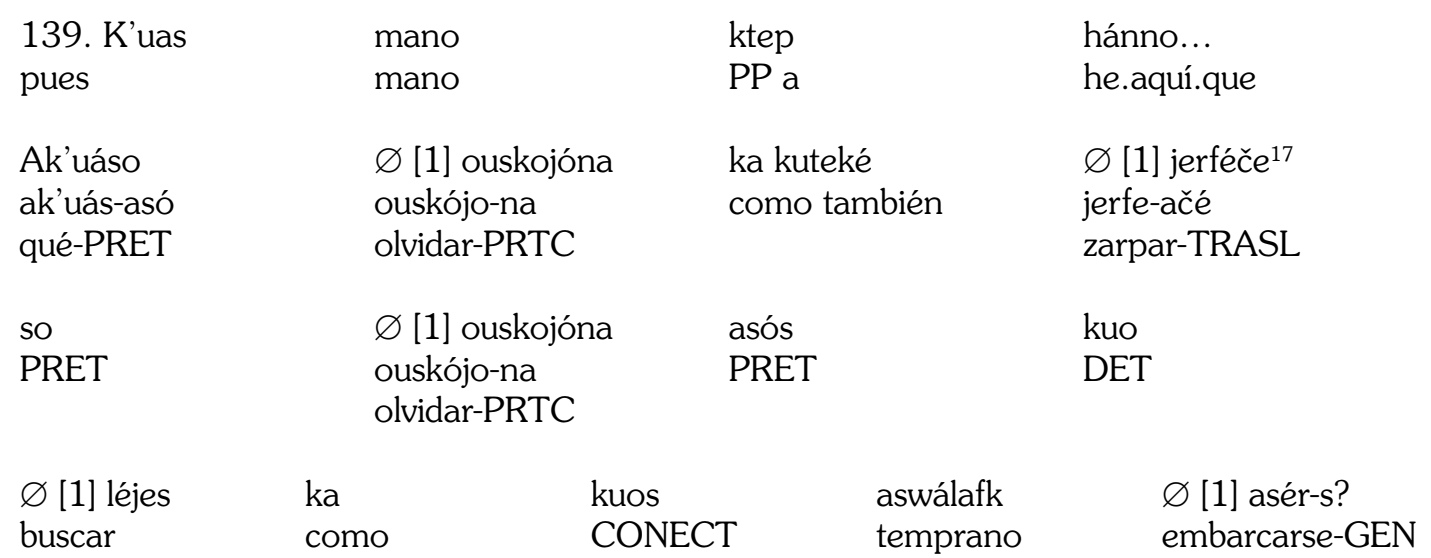

139. Pues con la mano he aquí que... ¿Qué cosa $\varnothing$ [1] habrá olvidado, qué cosa $\varnothing$ [1] dejó olvidada y $\varnothing[1]$ salió a buscarla muy temprano?
140. Jeksólok [1]
ak'uás
aksáwe
léjes-qei-so-kuer
finado
que
lobería
buscar-para-PRET-EVID

140. El finado [1] que había ido a buscar el paraje de lobos

A pesar de que jeksólok significa finado y pudiera haber servido de identificador de Peyáu, el verbo del cual es sujeto contiene el pluralizador -atal, despejando toda ambigüedad.

17 = zarpar habiendo desarmado el campamento o bien zarpar una cuadrilla mientras otra u otras quedan en el campamento. 
141. $\varnothing[1]$ asér

embarcarse

141. $\varnothing[1]$ se fue.

142. $\varnothing$ [1] Aqájeks-qei-so-koná-ker zarpar.remando-PROB-PRET-PRESUN-DUR

aswálafk

temprano
$\varnothing[1]$ aqájeks
zarpar.remando
a mano
woksterrék
ambos

142. Se habrá $\varnothing$ [1] ido remando muy temprano, $\varnothing$ [1] remando con ambas manos.

(Aguilera-Tonko, 2008a: T.SA-290307)

Factores culturales en la

determinación de la referencia

Hay factores culturales que intervienen en la manera que el narrador pone en escena a una persona cuya identificación depende del conocimiento previo que comparten el narrador y sus oyentes. Quien no tenga este conocimiento no puede saber de quién se está hablando. Este conocimiento previo incluye factores culturales que tienen que ver con las relaciones interpersonales de miembros de la etnia exclusivamente o con personas ajenas a ella y, por otro lado, con las relaciones de parentesco entre los participantes. En el caso de factor cultural, por ejemplo, encontramos muchas veces que en la narración hay una cita directa que concluye con la forma canónica æesk'ák = así [dijo]; sin embargo, no hay ninguna referencia a quién se refiere. A veces es posible (20)

$\begin{array}{llll}\begin{array}{l}\text { 540. Kuosá } \\ \text { CONECT }\end{array} & \begin{array}{l}\text { čo } \\ \text { yo }\end{array} & \begin{array}{l}\text { sepplalái: } \\ \text { preguntar }\end{array} & \begin{array}{l}\text { "Ak'uáso } \\ \text { ak'uás-asó } \\ \text { qué-PRET }\end{array} \\ \begin{array}{l}\text { hannó } \\ \text { he.aquí.que }\end{array} & \begin{array}{l}\text { jetæél-aká?", } \\ \text { andar-INTERROG }\end{array} & \begin{array}{l}\text { æesk'ák, } \\ \text { así }\end{array} & \begin{array}{l}\text { kuosá } \\ \text { CONECT }\end{array} \\ \begin{array}{l}\text { mæelčéksta } \\ \text { saber }\end{array} & \begin{array}{l}\text { kárieks } \\ \text { de.buen.sabor }\end{array} & \begin{array}{l}\text { os } \\ \text { pensar }\end{array} & \text { čo } \\ & & \text { yo }\end{array}$

540. Y yo pregunté: “Qué es esto?”, así [dije], y pensé que tenía buen sabor, yo necesariamente a la madre:

determinar a quién pertenece la cita porque un participante ha permanecido activado durante esa sección del relato, pero si ha habido una discontinuidad producto de una descripción que abarca un número importante de oraciones, o bien porque hay un nuevo episodio, para quien no sea kawésqar no le es posible determinar quién habla.

En los relatos de viaje quien tiene la autoridad y toma desiciones durante la navegación es el dueño o "patrón" de la embarcación, de modo que si hay una cita directa sin referencia, quien habla es esta persona. En las relaciones de parentesco, quien tiene la autoridad dentro de la vivienda temporal, por ejemplo, es la madre, de manera que ésa es la indicación de quien habla. En el siguiente ejemplo, la autoridad inmediata de la narradora es su madre, de manera que aunque no se trate de órdenes directas, diálogos o intervenciones con cita directa remiten 


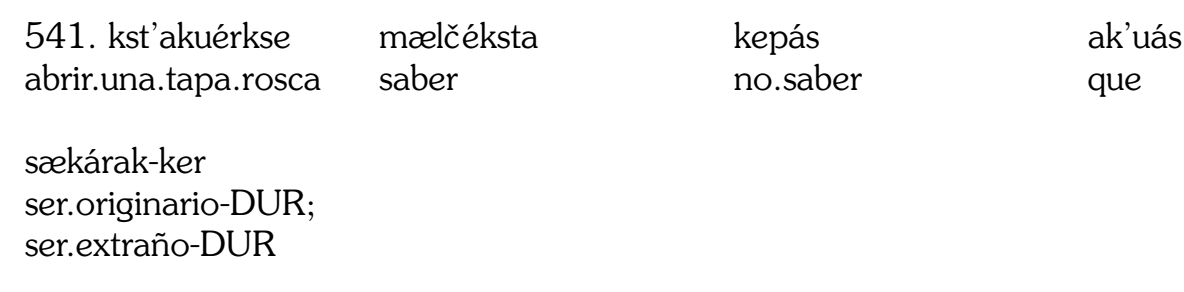

541. lo abrí y lo probé, no sabía lo que era, era extraño.

$\begin{array}{llll}\begin{array}{l}\text { 542. "Aikiát," } \\ \text { no.saber }\end{array} & \begin{array}{l}\text { æesk'ák, } \\ \text { así }\end{array} & \begin{array}{l}\text { "ka } \\ \text { como }\end{array} & \begin{array}{l}\text { ku } \\ \text { DET }\end{array} \\ \begin{array}{l}\text { táu-s } \\ \text { INTERROG-GEN }\end{array} & \begin{array}{l}\text { harečél } \\ \text { tomar }\end{array} & \begin{array}{l}\text { estar } \\ \text { aćáal }\end{array} \\ \begin{array}{l}\text { askét... } \\ \text { este.que... }\end{array} & \begin{array}{l}\text { laálte } \\ \text { nutria }\end{array} & \begin{array}{l}\text { káwes } \\ \text { piel }\end{array} & \text { ka } \\ \text { akiói } & \text { séwel-s } & \text { ahé?", } & \text { como } \\ \text { cambiar } & \text { no-GEN } & \text { ¿cierto? } & \text { resk'ák } \\ \end{array}$

542. "No sé”, así [dijo], “lo trajeron este que... a cambio de las pieles de nutria, ¿no?”, así [dijo].

$\begin{array}{llll}\begin{array}{l}\text { 543. "Laálte } \\ \text { nutria }\end{array} & \begin{array}{l}\text { káwes } \\ \text { piel }\end{array} & \begin{array}{l}\text { akióik } \\ \text { akiói-k } \\ \text { cambiar-LOC }\end{array} & \begin{array}{l}\text { har } \\ \text { tomar }\end{array} \\ \begin{array}{lll}\text { jemmáu } & \text { kep } & \text { háræer, }\end{array} & \text { æesk'ák } \\ \text { hombre.blanco } & \text { no } & \begin{array}{l}\text { har-ær } \\ \text { tomar-DUR }\end{array} & \text { así }\end{array}$

543. "Lo cambiaron por pieles de nutria, los blancos no lo darían por nada," así [dijo].

(Aguilera-Tonko, 2008a: T.SA-290307)

El otro caso de referencia difusa son las relaciones de parentesco de los participantes. Muchas veces éstos no son presentados con un nombre, sino con un identificador de parentesco (el padre o la madre de X; la abuela de Y, etc.), pero el identificador no es uno sólo y frecuentemente las referencias se cruzan, de manera que quien no conozca la relaciones de parentesco puede pensar que se trata de dos o más personas diferentes cuando en realidad es la misma.

Por ejemplo, en un relato se identifica a un personaje como Petéjen tawaisélok-s c'ap tawaisélok
= la difunta mamá del difunto Petéyen (§ 177) y más adelante (§ 309) se menciona a Patricia-s k'éwe-s tawaisélok = la finada abuela materna de Patricia. No es posible saber que se trata de la misma persona, sólo se conoce esto mucho más adelante en el relato en un episodio donde se cuenta un incidente en la carpa de al lado de la narradora donde los protagonistas principales son Panchote y la mamá de Petéyen, que era su pareja (§ 336): (21) 


$\begin{array}{llll}\begin{array}{l}\text { 177. kuos } \\ \text { CONECT }\end{array} & \begin{array}{l}\text { jeksólok-sélas } \\ \text { finado-FEM }\end{array} & \begin{array}{l}\text { tawaisélok [1] } \\ \text { difunto }\end{array} & \begin{array}{l}\text { ak'uás } \\ \text { que }\end{array} \\ \begin{array}{l}\text { askét... } \\ \text { este.que... }\end{array} & \begin{array}{l}\text { kuteké } \\ \text { Petéjen }\end{array} & \begin{array}{l}\text { tawaisélok-s } \\ \text { difunto-GEN }\end{array} \\ \begin{array}{l}\text { c'ap } \\ \text { mamá }\end{array} & \begin{array}{l}\text { ANTROPON } \\ \text { difunto }\end{array} & \begin{array}{l}\text { kuos } \\ \text { CONECT }\end{array} & \begin{array}{l}\text { jetźl [2] } \\ \text { andar }\end{array} \\ \text { kuos } & \begin{array}{l}\text { aqasektál-s[1, 2] } \\ \text { CONECT }\end{array} & \begin{array}{l}\text { kiáu } \\ \text { también }\end{array} & \\ & \text { remar-PAS-GEN } & & \end{array}$

177. y las desaparecidas difuntas [1] que este que... y la difunta mamá del difunto Petéyen [2] andaba [2], andaban navegando a remo [1, 2] también.

\begin{tabular}{|c|c|c|}
\hline $\begin{array}{l}\text { 309. Háuk } \\
\text { háu-k } \\
\text { al-lado-LOC }\end{array}$ & $\begin{array}{l}\text { sa } \\
\text { PP.TOP }\end{array}$ & $\begin{array}{l}\text { at } \\
\text { carpa }\end{array}$ \\
\hline $\begin{array}{l}\text { ksélksta-akstá } \\
\text { gritar-POT-D }\end{array}$ & efinido], & \\
\hline
\end{tabular}

309. Desde la carpa de al lado [alguien] [ $\varnothing$ indefinido] gritó,
310. ko
ak'uás
Patricia-s
k'éwe-s
DET pues
ANTROP-GEN
abuela.materna-GEN

tawaisélok. [2]

difunto

310. era la finada abuela materna de Patricia [Messier] [2].

$\begin{array}{llll}\begin{array}{l}\text { 330. Kuosá } \\ \text { CONECT }\end{array} & \begin{array}{l}\text { zes ... } \\ \text { mi... }\end{array} & \begin{array}{l}\text { jeksólok } \\ \text { difunto }\end{array} & \begin{array}{l}\text { Panchote } \\ \text { ANTROPON }\end{array} \\ \begin{array}{l}\text { tawaisélok [3] } \\ \text { finado }\end{array} & \begin{array}{l}\text { jerwó [3] } \\ \text { mandar }\end{array} & \begin{array}{l}\text { kettás [3] } \\ \text { enojarse }\end{array} & \begin{array}{l}\text { ak'uás } \\ \text { que }\end{array} \\ \begin{array}{l}\text { aselái [3] } \\ \text { decir }\end{array} & \begin{array}{l}\text { aselái-er-s [3] } \\ \text { decir-DUR-GEN }\end{array} & \begin{array}{l}\text { kok } \\ \text { cuando }\end{array}\end{array}$

330. Y mi... el finado, el difunto Panchote [3] mandó y [3] se enojó, [me] contó [3], cuando [me lo] contó [3], 


$\begin{array}{lcll}\begin{array}{l}\text { 331. [3] asahák } \\ \text { ase-ahák } \\ \text { decir-PROG }\end{array} & \begin{array}{l}\text { [3] wesahák-er-hójok } \\ \text { wese-ahák-DUR-PRET.NARR } \\ \text { reprender-PROG-DUR-PRET.NARR }\end{array} & \text { sa } & \text { PP.TOP } \\ \begin{array}{lll}\text { Panchote } & \text { tawaisélok } & \text { wa [3] } \\ \text { ANTROPON } & \text { finado } & \text { PP.CAMB.TOP. }\end{array} & \text { difunto }\end{array}$

331. diciendo [3] [que] había estado retando [3] al difunto [4]; por su parte el finado Panchote [3]

$\begin{array}{llll}\text { 332. kuos } & \text { kius [3] } & \text { jerwásqe [4] } & \text { ak'uás } \\ \text { CONECT } & \text { su } & \text { el.que.se.manda } & \text { que }\end{array}$

$\begin{array}{lll}\begin{array}{l}\text { aselájer-s }[\varnothing \text { indefinido] } \\ \text { aselái-er-s }\end{array} & \begin{array}{c}\text { kuos } \\ \text { CONECT }\end{array} & \begin{array}{l}\text { eik'osektálæer-hójok [ } \varnothing \text { indefinido] } \\ \text { eik'ose-sektál-əer-hójok }\end{array} \\ \begin{array}{l}\text { askét... } \\ \text { este que... }\end{array} & \begin{array}{l}\text { Petéjen } \\ \text { contar-PAS-DUR-PRET.NARR }\end{array} & \text { tawaisélok [4] } \\ & \text { ANTROPON } & \text { finado }\end{array}$

332. se dice que su mandado ${ }^{18}$ era este que... el finado Petéyen, se cuenta.
333. [4] Kuo
[3] arrasé-keséktal
DET arrasé-ker-séktal
[3] jerwosektálæer-hójok-s [4Ø] jerwo-sektál- ær-hójok-s querer-DUR-PAS mandar-PAS-DUR-PRET.NARR-GEN

kuos

CONECT

333. [4] Le [3] tenía mucho cariño y [4] lo [3] mandaba.

334. Kuo

DET

ak'uás

qué

$\mathrm{ke}$ ?

sa

PP.TOP čečáu-jetá-kettás-qei-hójok [3]

PREF.REFL-hacer-enojar-PROP-PRET. NARR

334. ¿Por qué se habrá enojado[3]?

335. Jet...

ERR.DIC

čečáu-setqána

PREF.REFL-instalado čekék

venir jelái-s ver-GEN kst'atqána-s desprendido.habiendo.agarrado. con.la.mano-GEN kok

cuando 
woks [2, 3]

dos

335. Cuando llegué [al campamento] vi que habían desprendido la cubierta de la carpa de un tirón y [ahí] estaban discutiendo los dos difuntos [2, 3]:

$\begin{array}{lllll}\begin{array}{l}\text { 336. kuosá } \\ \text { CONECT }\end{array} & \begin{array}{l}\text { jeksólok-sélas [2] } \\ \text { difunto-FEM }\end{array} & \begin{array}{l}\text { kuos } \\ \text { CONECT }\end{array} & \begin{array}{l}\text { Petéjen } \\ \text { ANTROPON }\end{array} & \begin{array}{l}\text { c'ap } \\ \text { mamá }\end{array} \\ \begin{array}{l}\text { tawaisélok [2] } \\ \text { finado }\end{array} & \begin{array}{l}\text { tawaisélok [3] } \\ \text { finado }\end{array} & \begin{array}{l}\text { kuos } \\ \text { CONECT }\end{array} & \begin{array}{l}\text { kius [3] } \\ \text { su }\end{array} & \begin{array}{l}\text { sejóra } \\ \text { señora }\end{array} \\ \begin{array}{l}\text { kius [3] } \\ \text { su }\end{array} & \begin{array}{l}\text { c'éwek } \\ \text { pareja }\end{array} & \text { jetzél [2] } & & \\ \end{array}$

336. Ia difunta [2], mamá del difunto Petéyen [2] y el difunto [3], [ella] [2] era su [3] señora, su [3] pareja.

(Aguilera-Tonko, 2008a: T.SA-290307)

Uso de pronombres

El kawésqar es una lengua SOV que presenta sujetos nulos $[\varnothing]$, con un sistema pronominal que tiene cierta similitud con el shipibo (cf. Camacho \& Elías-Ulloa, 2010) en el sentido que sólo los pronombres de 1a. y 2 a. persona deben ser expresos, en tanto que los de tercera persona pueden ser nulos ${ }^{19}$. No obstante, en kawésqar la totalidad de los pronombres sujeto en plural son nulos. Los pronombres objetos son nulos en plural en la 1a. y 2 a. personas, no así en la 3a. persona, aunque también se dan como nulos.

\section{PRONOMBRES SUJETOS}

\begin{tabular}{|c|c|c|}
\hline $1 . \mathrm{sg}$. & $2 . \mathrm{sg}$. & $3 . \mathrm{sg}$. \\
\hline če (+ V. intr.) & čáu & $\varnothing$ (tóu, kiut) \\
\hline čo (+ V. tr.) & & \\
\hline $1 . \mathrm{pl}$. & $2 . \mathrm{pl}$. & $3 . \mathrm{pl}$ \\
\hline$\varnothing$ & $\varnothing$ & $\varnothing$ (tóu, kiut) \\
\hline
\end{tabular}

19 "As first noted by Elías-Ulloa (...) for Capanahua, Pano languages have a mixed null-subject system. Like Hebrew and Finnish, Shipibo also groups 1st. and 2nd. persons vs. 3rd. person, but the pattern is the opposite: 1st. and 2nd. person subjects must be overt, 3rd. person can be null." (Camacho \& Elías-Ulloa op.cit: 69).
En 3a. persona singular en ocasiones se utilizan como pronombres tóu otro o kiut el último, este último.

\section{PRONOMBRES OBJETOS}

\begin{tabular}{|c|c|c|}
\hline $1 . \mathrm{sg}$. & 2. sg. & 3.sg. \\
\hline æs & čáu & kius, $\varnothing$ \\
\hline & & \\
\hline $1 . \mathrm{pl}$. & $2 . \mathrm{pl}$. & $3 . \mathrm{pl}$ \\
\hline$\varnothing$ & $\varnothing$ & kius, $\varnothing$ \\
\hline
\end{tabular}

Respecto a la referencia, en ocasiones puede producirse confusión, pero es posible eliminar la ambigüedad si se toma en cuenta la referencia contextual, es decir, si hay alguna información previa que sirva para verificar la referencia. En el siguiente ejemplo, en $\S 10$ se había informado que el hermano de la narradora la había llevado a cazar hacia el sur y ésa es la información que sigue vigente y permite establecer a quién se refiere kiut en $\S 20$; los números en corchetes remiten a las personas mencionadas, en paréntesis se indican los pronombres: 
(22)
18. Jeksólok [1]
ak'uás
kséptæel
finado
pues
caminar

18. El finado [1] era andador,

$\begin{array}{lll}\text { wáskar } & \text { tqalp } & \text { (3. sg. } \varnothing)[1] \text { jétqa-ketálap } \\ \text { cerro } & \text { tqal-p } & \text { jétqa-ketźl-ap } \\ & \text { terreno.plano-hacia } & \text { subir-HAB-AGEN }\end{array}$

(3.sg. Ø) [1] subía por los cerros,

$\begin{array}{llllll}\text { kius [1] } & \text { aihiól } & \text { hójok } & \text { kuos } & \text { Čerkuáp-s [2] } & \text { [jenák] } \\ \text { su } & \text { hijo } & \text { PRET.NARR } & \text { CONECT } & \text { ANTROPON- } & \text { [ser/estar] } \\ & & & \text { GEN } & \end{array}$

su [1] hijo [es] Čerkuáp [2],

$\begin{array}{ll}\text { arkáu } & \text { (3.sg. Ø) [2] jestál } \\ \text { arriba } & \text { andar }\end{array}$

(3.sg. Ø) [2] anda arriba [en la turbera],

(3.sg. Ø) [2] čekék-kerák

venir-HAB

(3.sg. Ø) [2] siempre retorna,

$\begin{array}{lll}\text { kawésqar } & \text { serkskuéna } & \text { (3.sg. } \varnothing) \text { [2] [jenák] } \\ \text { persona } & \text { perezoso } & \text { [ser/estar] }\end{array}$

(3.sg. Ø) [2] [es] una persona floja y

$\begin{array}{llll}\text { ka } & \text { woksterré } & \text { zes-c'éwe-terrép } & \text { kepásna-er-k'éna } \\ & \text { woks-terre } & \text { zes-c'éwe-terre-p } & \\ \text { como } & \text { dos-DIREC } & \text { para-mí-terreno.a.pique- } & \text { borracho-DUR-HAB } \\ & \text { de.un.lado.a.otro } & \text { DIR-hacia }{ }^{21} & \end{array}$

(3.sg. Ø) [2] jetátal-k'enák andar-HAB

(3. sg.Ø) [2] anda aquí de un lado a otro borracho.
19. Kius[2]
čačár[1]
jetál-hójok
su
papá
andar-PRET.NARR

21 En deícticos æes- para mí corresponde al centro deíctico, i.e. yo en relación a lun terreno a pique, un terreno en declive, un canal, etc.]. 
19. Su [2] padre [1] estaba vivo,

$\begin{array}{lllllll}\text { kuos } & \text { kuosá } & \text { tákso-s } & \text { kius } & \text { táu-s } & \text { aksánas } & \begin{array}{l}\text { (3. sg. } \varnothing) \text { [1] [jenák- } \\ \text { hójok] }\end{array} \\ \text { CONECT } & \text { CONECT } & \text { uno-GEN } & \text { su } & \text { único-GEN hombre } & \begin{array}{l}\text { [ser/estar-PRET. } \\ \text { NARR] }\end{array}\end{array}$

(3. sg.Ø) [1] [era] el único hombre [de nuestra familia].

$\begin{array}{lclc}\text { 20. Kiut [1] (3.sg.) } & \text { če } & \begin{array}{l}\text { ksersekuás-er-hójok seté } \\ \text { kser-sekuás-er-hójok } \\ \text { invitar-embarcarse-DUR- su } \\ \text { él }\end{array} \quad \text { yo } & \end{array}$

$\begin{array}{llll}\text { kiās... } & \text { woksterré } & \text { æes-kstái } & \text { hápar } \\ \text { allá } & \begin{array}{l}\text { woks-terre } \\ \text { dos-DIREC }\end{array} & \text { para-mí-canal } & \text { hacia } \\ & \text { de.un.lado.a.otro } & \end{array}$

20. Él [1] me llevó invitada para allá a los canales del sur, de allá para acá.

(Aguilera-Tonko, 2008a: T.PE-MIT-011206)

En el siguiente ejemplo tenemos uso de un pronombre, pero aplicado la primera vez a ciertas personas y la segunda a otras:

337. Hō

EXCLAM

kiáno

kuos

kep

he.aquí.que

CONECT

no

akstá-kečéjer

Alessanri [1]

akstá-ker-ačé-er

ANTROPON

POT-DUR-TRASL-DUR

337. He aquí que se estaba demorando Alessandri [1],

(3.sg. Ø) [1] kskenák

huir (3.pl. Ø) [2] aselái-akstá-kečéjer

aselái-akstá-ker-ačé-er

decir-POT-DUR-TRASL-DUR

dicen (3.pl. Ø) [2] que (3.sg. Ø) [1] escapó

$\begin{array}{llll}\text { kuos } & (3 . s g . \text { OBJ } \varnothing)[1] \text { jeksór } & \text { k'élok } & \text { (3.sg. pl. } \varnothing) \text { [2] asahák } \\ \text { CONECT } & \text { ver } & & \begin{array}{l}\text { asa-ahák } \\ \text { decir-PROG }\end{array}\end{array}$

y (3.sg. pl. Ø) [2] dicen que no [lo] (3.sg. OBJ Ø) [1] habían visto, 
asesekčál-k'ejehák-er

ase-sekčál-k'ejehák-er

decir-traer-HAB-DUR

así llegaba la información,

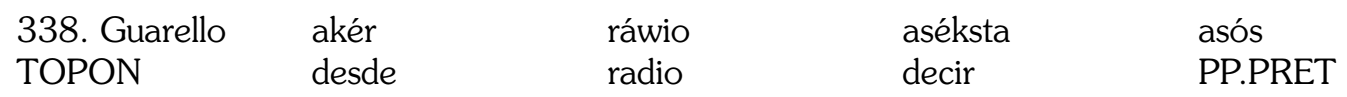

338. desde Guarello la radio había comunicado.

339. (3.sg. OBJ Ø) [1] (3.pl. Ø) [3] Jewóna-k'ejehák no.encontrar-HAB

339. (3.sg. OBJ Ø) [1] [Lo] (3.pl. Ø) [3] buscaban en vano,

$\begin{array}{llll}\text { kupép } & \text { kiut [3] } & \text { k'exátauk } & \text { jaláu } \\ \text { también } & \text { ellos } & \text { k'exátau-k } & \text { entonces } \\ & & \text { finalmente-LOC } & \end{array}$

$\begin{array}{llllll}\text { asáqe } & \text { ka kuteké } & \text { awélqe } & \text { kuteké } & \text { wal } & \text { táwon } \\ \text { comida } & \text { como también } & \text { ropa } & y & \text { cosa } & \text { con }\end{array}$

\begin{tabular}{|c|c|c|c|c|}
\hline čelkuálo & & & čelkuolái & jektǽl-kelái \\
\hline ERR.DIC & & & salir.en.embarcación & buscar-PUNT \\
\hline & ku & táwon & (3.sg. OBJ $\varnothing)[1]$ & 1. Ø) [3] alákso-qei \\
\hline PP.REF & DET & con & dar-PROP & \\
\hline
\end{tabular}

también ellos [3] finalmente con comida, ropa y con cosas [lo] (3.sg. OBJ) $\varnothing$ [1] buscaban en embarcación para que pudiesen (3.pl. ) [3] aprovisionar[lo] (3.sg.OBJ Ø) [1],
340. kuosá
CONECT
kiut [4]
ellos
(3.sg. OBJ $\varnothing)$ jetalái
ka kuteké
molestar como también

(3.sg. OBJ Ø) kst'ap-aksó-kelái encerrar-armado-PUNT ${ }^{22}$

k'élok

no

os

PROP

340. para que ellos [4] no [lo] (3.sg. OBJ Ø) [1] pudiesen tocar ni llevar preso,

\begin{tabular}{|c|c|c|c|}
\hline $\mathrm{ka}$ & $\begin{array}{l}\text { (3sg. OBJ Ø) [1] (3.pl. } \\
{[3] \text { jeksórk }}\end{array}$ & at & ka kuteké \\
\hline cuando & $\begin{array}{l}\text { jeksór-k } \\
\text { ver-LOC }\end{array}$ & casa & como también \\
\hline palánča & táwon & $\begin{array}{l}\text { (3sg. OBJ Ø) [1] (3.pl. os } \\
\varnothing)[3] \text { čejékso }\end{array}$ & \\
\hline
\end{tabular}


$\begin{array}{lll}\text { plancha con } \quad \text { construir } & \text { PROP }\end{array}$

también cuando [lo] (3sg. OBJ Ø)[1] (3.pl. Ø) [3] encontraran [querían entregarle] una casa y planchas para construir

\begin{tabular}{|c|c|c|}
\hline $\begin{array}{l}\text { čejétar } \\
\text { construir }\end{array}$ & $\begin{array}{l}\text { ko } \\
\text { DET }\end{array}$ & $\begin{array}{l}\text { at } \\
\text { casa }\end{array}$ \\
\hline
\end{tabular}

para que construida pudiese (3 sg. Ø) estar en la casa

ka (3.pl. Ø) [3] (3. sg. OBJ Ø) [1] jewóna-k’ejehák

pero no.encontrar-HAB

(3.pl. Ø) [3] aséksta-kóna-kečéjer

aséksta-kona-ker-ačé-er

decir-PRESUN-DUR-TRASL-DUR

pero (3.pl. Ø) [3] decían que no [lo] (3. sg. OBJ Ø) [1] (3.pl. Ø) habían encontrado.

(Aguilera-Tonko, 2008a: T.PE-MIT-011206)

Aquí en § 337, el sujeto de aselái-akstá-kečéjer (decir-POT-DUR-TRASL-DUR) es indefinido, por lo cual se señala con 3.pl. $\varnothing$ [2], al igual que para las otras oraciones de este segmento; sin embargo, 3.pl. $\varnothing[3]$ en $\S 339$ y el pronombre kiut $=$ ellos, se refiere a la gente que trabaja en Guarello. El pronombre kiut $=$ ellos de $\S 340$ se señala como [4] porque se refiere a la gente de la Armada que quería llevar preso a [1]. Hay un cambio de referencia usando el mismo pronombre, sin embargo, como se describen acciones contrarias que afectan a [1], para el hablante no hay dificultad de comprensión.

Presencia o ausencia del pluralizador verbal -atál

El siguiente caso de dificultad para interpretar la referencia de personas tiene que ver con la presencia o ausencia del pluralizador verbal -atál. El uso de este pluralizador es optativo; por lo general se elide cuando el sujeto es claramente plural porque las acciones expresadas en la oración u oraciones no pueden ser ejecutadas por una sola persona. Cuando no se elide y no hay un sujeto plural expreso, remite a un sujeto plural indefinido (v. (26) más abajo).

En el siguiente ejemplo, en $\S 455$ el pronombre če = yo da cuenta de quién habla en la cita directa. Se podría pensar que al haber referencia $\varnothing$ en las oraciones siguientes sigue rigiendo če, sin embargo aquí $\varnothing$ remite a un plural tácito "nosotros" que se explica culturalmente porque una sola persona no podría andar en un viaje de caza prolongado a través del territorio kawésqar:
455. Jáuk

jáu-k

tierra-LOC

455. "Ya hemos llegado a tierra”, así pensé.

456. Kuosá

séjep

lói-qei-kuor

æesk'ák

llegar-PROP-EVID así os

pensar če

yo ker DUR

CONECT hacia.abajo andar

Rapel
TOPON

tqal-s

aqásk

terreno.en.forma. aqás-k de.bahía-GEN

remar-LOC 
456. Íbamos hacia el sur, al lugar llamado Rapel,

$\begin{array}{llll}\text { 457. tqalk } & \begin{array}{l}\text { kst'apón } \\ \text { chilote }\end{array} & \text { awóqa } & \text { awo-aqás } \\ \text { tqal-k } & \text { encender-COMPL } & \text { estar } \\ \text { terreno.en.forma.de.bahía-LOC } & & \end{array}$

457. pensábamos que íbamos a encontrar el campamento de los chilotes.

$\begin{array}{llll}\text { 458. Kuo } & \text { fsek } & \text { čečél } & \text { sos } \\ \text { DET } & \text { fse-k } & \text { estar } & \text { PP.PRET } \\ & \text { quieto-LOC } & & \\ \text { kutálak } & \text { séjep } & \text { hápar } & \\ \text { hacia.adelante } & \text { hacia.abajo } & \text { hacia } & \end{array}$

458. Después de haber estado ahí seguimos más adelante hacia el sur.

(Aguilera-Tonko, 2008a: T.SA-290307)

Un caso similar se aprecia en (25), en donde la tarea de extraer la carne de una ballena varada no puede ser ejecutada por una sola persona. Como se dijo anteriormente, quien habla en la cita directa es el dueño de la canoa, aunque no se lo menciona:

(25)

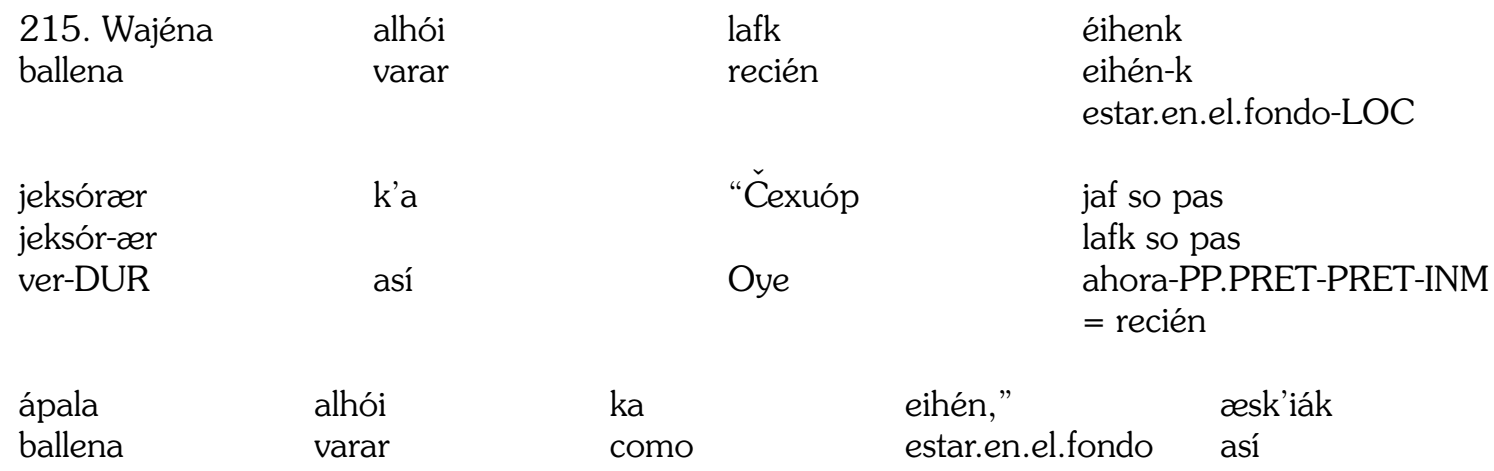

215. Vimos una ballena recién varada: "Oye, mira que recién habrá varado la ballena que está ahí", así [dijo].

$\begin{array}{llll}\text { 216. Kuosá } & \begin{array}{l}\text { jelájer-s } \\ \text { jelái-er-s }\end{array} & \text { kius } & \text { áfqe } \\ \text { CONECT } & \text { ir.a.buscar-DUR-GEN } & \text { su } & \text { parte.delantera } \\ & \text { c'ói } & \begin{array}{l}\text { kiarlái-er-s } \\ \text { denominar-DUR-GEN }\end{array} & \text { kuo } \\ \text { ka kuteké } \\ \text { como también } & \text { parte.delantera }\end{array}$




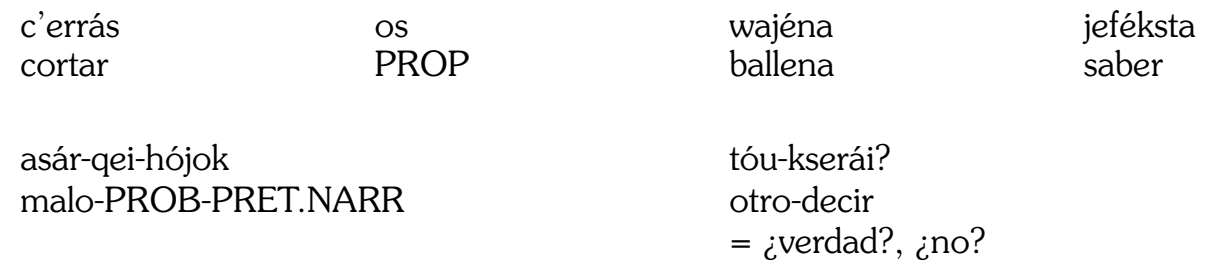

216. Y fueron a buscar la parte delantera que se llama c'ói, para cortarla, la ballena sabe mal, ¿no? ${ }^{23}$

(Aguilera-Tonko, 2008a: T.SA-290307)

En (26) se hace necesaria la inclusión del pluralizador verbal en $\S 17$, puesto que de lo contrario se podría interpretar que sigue rigiendo el mismo sujeto de $\S 14$, Alfredo, ya que la acción expresada en $\S$ 17 bien podría haber sido ejecutada por esta persona aunque los tiempos de la acciones son diferentes (antes - hoy). En este caso el pluralizador -atál remite a un sujeto plural indefinido tácito:

$\begin{array}{llclc}\begin{array}{l}\text { 14. Alfredo } \\ \text { ANTROPON }\end{array} & \begin{array}{l}\text { tawaisélok } \\ \text { finado }\end{array} & \begin{array}{l}\text { sa } \\ \text { PP.TOP }\end{array} & \begin{array}{l}\text { kuos } \\ \text { CONECT }\end{array} \\ \text { askét... } & \begin{array}{l}\text { altálap } \\ \text { által-ap } \\ \text { trabajar-AGEN } \\ \text { este.que... }\end{array} & \begin{array}{l}\text { lejésk } \\ \text { léjes-k } \\ \text { buscar-LOC }\end{array} & \text { jerwókta-s } \\ & \text { jetátal } & & \text { mandar-GEN } \\ \text { ka kuteké } & \text { andar } & \text { ačáal } & \text { hójok } \\ \text { como también } & \text { PP.REF } & \text { PRET.NARR }\end{array}$

14. El finado Alfredo era el que buscaba a su este que... trabajadores, los mandaba y [ahí] andaba,

$\begin{array}{lllll}\text { 15. ku } & \text { táusa } & \text { sa } & \text { čekék-kejétal } & \text { wæes } \\ \text { DET } & \text { sólo } & \text { PP.TOP } & \text { venir-FREC } & \text { tierra }\end{array}$

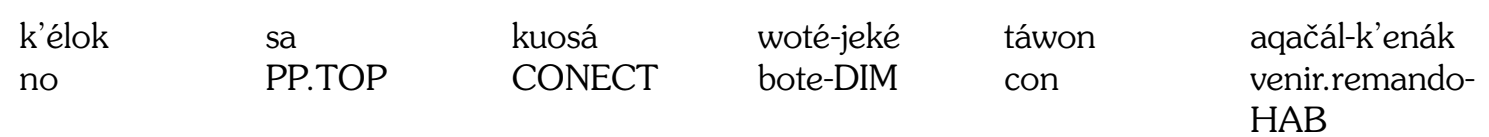

15. solamente él llegaba y no venía por tierra sino que venía en un botecito.

\begin{tabular}{|c|c|c|c|c|}
\hline $\begin{array}{l}\text { 16. Jaláu } \\
\text { antes }\end{array}$ & $\begin{array}{ll}\text { wa } & \text { terió } \\
\text { PP.CAMB.TOP camino }\end{array}$ & $\begin{array}{l}\text { kiáwel } \\
\text { sin }\end{array}$ & $\begin{array}{l}\text { ačáal } \\
\text { PP.REF }\end{array}$ & $\begin{array}{l}\text { hójok } \\
\text { PRET.NARR }\end{array}$ \\
\hline $\begin{array}{l}\text { kuosá } \\
\text { CONECT }\end{array}$ & $\begin{array}{l}\text { woté-jeké } \\
\text { bote-DIM }\end{array}$ & $\begin{array}{l}\text { asék } \\
\text { asé-k } \\
\text { embarca }\end{array}$ & $\begin{array}{l}\text { aq } \\
\text { vel }\end{array}$ & $\begin{array}{l}\text { nák } \\
\text { ando-HAB }\end{array}$ \\
\hline
\end{tabular}

16. Antes no había camino y venía en botecito, 


\begin{tabular}{|c|c|c|c|c|}
\hline $\begin{array}{l}\text { 17. lafk } \\
\text { hoy }\end{array}$ & $\begin{array}{l}\text { terióna } \\
\text { terió-na } \\
\text { camino-PRTC }\end{array}$ & $\begin{array}{l}\text { ja } \\
\text { haber }\end{array}$ & $\begin{array}{l}\text { kče... } \\
\text { ERR.DIC }\end{array}$ & $\begin{array}{l}\text { kčeihéna } \\
\text { kče(jes)-eihén-na } \\
\text { construir-estar.en.el.fondo-PRTC } \\
=\text { construido }\end{array}$ \\
\hline
\end{tabular}

ksepahák-er-atál

ksep-ahák-er-atál

caminar-PROG-DUR-PL

17. hoy hay camino construido y por ahí caminan.

(Aguilera-Tonko, 2008a: T.SA-120407=1)

\section{CONCLUSIÓN}

En el presente trabajo se ha abordado la estructura general de los relatos de viaje kawésqar, con un enfoque antropológico-lingüístico, ilustrando sus componentes a través de ejemplos tomados del corpus elaborado. Los relatos de viajes comprendidos en una época en que el nomadismo de los kawésqar estaba plenamente vigente, permiten observar rasgos no documentados hasta hoy de este tipo de vida, al tiempo que despejan interrogantes acerca de las zonas de nomadismo, planteadas por autores tales como Emperaire y Gusinde.

Por otro lado, se examinó la referencia a los participantes en este tipo de narraciones. Para ello se utilizó el patrón de la distancia referencial a fin de determinar cuáles eran las formas utilizadas en la referencia. Se observó que las referencias a personas pueden estar representadas por un nombre propio, un sustantivo o una frase nominal. La distancia referencial puede ser variable, pero en caso de que el hablante considere que la referencia puede ser difusa, la reactiva mediante un apelativo identificador. Una vez activada la referencia, ésta sigue vigente hasta la introducción de un nuevo participante. Se expuso, además, que en los casos en que había interferencia en la determinación de la referencia por parte del lector o no hablante kawésqar, era necesario tomar en cuenta factores culturales que tienen que ver con las relaciones interpersonales de miembros de la etnia exclusivamente o con personas ajenas a ella, asimismo con las relaciones de parentesco de los participantes.

El uso de pronombres sujetos nulos es otro factor que incide en la interferencia de la determinación de la referencia. Se dio cuenta del sistema pronominal kawésqar, que es un sistema mixto por el hecho de presentar sujetos y objetos nulos en las formas de plural, con excepción de la tercera persona, en donde el sujeto nulo es optativo. En kawésqar el verbo no tiene cambios morfológicos que permitan diferenciar singular o plural, a excepción de un marcador de plural -atal optativo, que se elide cuando el sujeto es claramente plural porque las acciones expresadas en la oración $u$ oraciones no pueden ser ejecutadas por una sola persona. Finalmente, cabe observar que este breve examen de los problemas tratados proporciona nuevos datos sobre esta lengua fueguina al borde de la extinción.

\section{ABREVIATURAS EN LOS TEXTOS GLOSADOS}

AGEN = agentivo

ANTROPON = antropónimo

COMPL $=$ completivo

CONECT $=$ conectivo

$\mathrm{DET}=$ determinante

$\mathrm{DIM}=$ diminutivo

$\mathrm{DIR}=$ dirección, direccional

DUR = durativo

ERR.DIC = error de dicción

EVID = evidencial

EXCLAM = exclamativo

$\mathrm{FEM}=$ femenino

GEN = genitivo

$\mathrm{HAB}=$ habituativo

INTERROG = interrogativo

LOC = locativo

PAS = pasivo

$\mathrm{PL}=$ plural 
POT $=$ potencial

PP.CAMB.TOP = partícula de cambio de tópico

PP.REF = partícula referencial

PP.TOP = partícula de tópico

PREF.REFL = prefijo reflexivo

PRESUN = presuntivo

PRET.INM = pretérito inmediato

PRET.NARR $=$ pretérito narrativo

$\mathrm{PROB}=$ probabilidad

$\mathrm{PROG}=$ progresivo

PROP $=$ propósito

PRTC $=$ participio, participial

PUNT = puntual

REFORZ = reforzativo

TOPON = topónimo

TRASL $=$ traslativo

\section{BIBLIOGRAFÍA ${ }^{24}$}

AGUILERA F., O. y J. TONKO P. 2008a. Archivo Sonoro de la Lengua Kawésqar. Punta Arenas: Gobierno Regional de Magallanes y Antártica Chilena, CONADI XII Región, FIDE XII. Registro digital en formato wav. Acceso parcial en: Aguilera, Oscar, Tonko, José. The Chilean Languages Collection, The Archive of the Indigenous Languages of Latin America: www.ailla.utexas.org. Media: audio, text, image. Access: 77\% restricted. (Copias del Archivo se encuentran en la Intendencia de la XII Región, Gobierno Regional de Magallanes y Antártica Chilena, Punta Arenas; Centro de Estudios del Hombre Austral, Universidad de Magallanes, Punta Arenas; Corporación Nacional de Desarrollo Indígena XII Región (CONADI), Punta Arenas; Biblioteca Nacional, Santiago; The Cairns Institute, James Cook University, Cairns, Queensland, Australia).

AGUILERA F., O. 2008b. Escenario en los relatos de viaje kawésqar, Onomázein 18 (2008/2): 49-74. Versión electrónica (pdf) en: www.onomazein.net/18.html y en: Aguilera, Oscar (Author). (2008). Setting in Kawésqar Travel Narratives. The Chilean Languages Collection. The Archive of the Indigenous Languages of Latin America:

24 La documentación bibliográfica en Internet se da de acuerdo a las especificaciones de referencia exigidas por los sitios que la contienen. www.ailla.utexas.org. Media: text. Access: public. Resource: ALC003R120. Filename: ALC003R120I001.pdf AGUILERA F., O. y J. TONKO P. 2009. Isla Kalau y Territorio Adyacente. Geografía Kawésqar. Acervo Cultural Kawésqar vol. 1. Punta Arenas: CONADI XII Región y FIDE XII. Edición de distribución limitada. Versión electrónica (pdf) en: Tonko, José (Author), Oscar Aguilera (Author). (2009). "Kalau Island and Adjacent Territory: Kawésqar Geography". The Chilean Languages Collection. The Archive of the Indigenous Languages of Latin America: www.ailla.utexas.org. Media: text. Access: public. Resource: ALC005R002. Filename: ALC005R002I001.pdf

AGUILERA F., O. y J. TONKO P. 2010. Relatos de Viaje Kawésqar. (MS).

CAMACHO, J., R. GUTIÉRREZ-BRAVO, L. SÁNCHEZ (Eds.). 2010. Information Structure in Indigenous Languages of the Americas. Syntactic Approaches. De Gruyter Mouton, Berlin/New York.

CAMACHO, J., J. ELÍAS-ULLOA. 2010. Null subjects in Shipibo switch-reference systems. En Information Structure in Indigenous Languages of the Americas. Syntactic Approaches. De Gruyter Mouton, Berlin/New York. CAMACHO, J. et al. (Eds.).

DOOLEY, R. A. y S. H. LEVINSOHN. 2001. Analyzing discourse. A manual of basic concepts. SIL International, Dallas.

EMPERAIRE, J. 1963. Los nómades del mar. Versión española. Ediciones de la Universidad de Chile, Santiago.

GIVÓN, T. (ed.). 1983. Topic Continuity in discourse: A quantitative cross-language study. John Benjamins, Amsterdam.

GIVÓN, T. 1984-90. Syntax: a functional-typological introduction. John Benjamins, Amsterdam.

MARTINIC B., M. 2004. Archipiélago Patagónico. La Última Frontera. Ediciones de la Universidad de Magallanes, Punta Arenas.

STANLEY, W. E. 2007. Referent Management in Olo: A Cognitive Perspective. SIL International, Dallas.

TONKO P., J. 2008. Relatos de viaje kawésqar, Onomázein 18 (2008/2): 11-47. Versión electrónica (pdf) en www.onomazein.net/18.html y en Tonko, José (Author). (2008). Kawéswar Travel Narratives. The Chilean Languages Collection. The Archive of the Indigenous Languages of Latin America: www.ailla.utexas.org. Media: text. Access: public. Resource: ALC003R121. Filename: ALC003R121I001.pdf 
